\title{
CD137 induces adhesion and cytokine production in human monocytic THP-1 cells
}

\author{
Jung-Won Choi ${ }^{1,2, *}$, Hyeon-Woo Lee $e^{2,3, *}$ \\ Gu-Seob Roh ${ }^{4}$, Hong-Hee $\mathrm{Kim}^{5}$ and \\ KyuBum Kwack ${ }^{1,2,6,7}$
}

${ }^{1}$ National Genome Research Institute National Institute of Health, KCDC

5 Nokbun-dong, Eunpyeong-gu, Seoul 122-701, Korea

${ }^{2}$ Immunomodulation Research Center

University of Ulsan

Ulsan 680-749, Korea

${ }^{3}$ Department of Pharmacology

School of Dentistry, Kyung Hee University

Seoul 130-301, Korea

${ }^{4}$ Department of Anatomy

College of Medicine, Gyeongsang National University

Jinju 660-751, Korea

${ }^{5}$ Department of Cell and Developmental Biology

Seoul National University, Dental School

Seoul 110-749, Korea

${ }^{6} \mathrm{CHA}$ Research Institute

Pochun CHA University

Seongnam 463-836, Korea

${ }^{7}$ Corresponding author: Tel, 82-31-725-8376;

Fax, 82-31-725-8350; E-mail, kbkwack@cha.ac.kr

${ }^{*}$ These authors contributed equally to this work.

Accepted 21 February 2005

Abbreviations: AML, acute myelocytic leukemia; ECM, extracellular matrix; ERK, extracellular signal-regulated kinase; MEK, mitogenactivated protein kinase kinase; PIGF, placenta growth factor; RT, reverse transcription

\footnotetext{
Abstract

CD137, which is expressed on activated T cells, plays a critical role in inflammatory responses. However, the exact role that CD137 plays in monocytes is not fully known. Here we studied the expression and function of CD137 in human monocytic THP-1 cells, which we found constitutively expresses CD137 at the mRNA and protein level. Cross-linking of CD137 increased the secretion of IL- 8 and TNF- $\alpha$, promoted the expression of CD54 and CD11b, and increased adhesion to extracellular matrix (ECM) proteins. In particular CD137-induced adhesion of THP-1 cells was
}

inhibited by an inhibitor of mitogen-activated protein kinase kinase (MEK), but not by a p38 kinase inhibitor. Taken together, these results show that the adhesion and cytokine production of THP-1 cells induced by CD137 occur via activation of MEK, which results in the activation of ERK-1/2 signaling pathways. Therefore, this study suggests that CD137 induces an activating and migrating signal during inflammatory processes.

Keywords: 4-1BB receptor; cell adhesion; kinases; inflammation; mitogen-activated protein; monocytes

\section{Introduction}

Inflammatory responses are initiated by the innate immunity of macrophages to counteract invading pathogens. Cytokines and chemokines are released by activated macrophages, and then the more expressed adhesion molecules promote the binding of circulating neutrophils and monocytes. Monocytes, which circulate in the blood, differentiate continuously into macrophages upon migration to the inflammation site. This innate immune response plays a crucial role in the $T$ lymphocyte mediated adaptive immune response (Janeway et al., 2001).

Monocytes have multiple physiological and morphological states, and mature macrophages have enhanced phagocytic activity. Deregulated monocyte activation has been implicated in rheumatoid arthritis and systemic lupus erythematosus (Traycoff et al., 1976; Gottlieb et al., 1979). Although monocytes may play an essential role in immune surveillance, the process of monocyte activation and especially the regulation of its diverse functions are only partially understood.

CD137 is present in immune cells such as activated $\mathrm{T}$ cells, monocytes, neutrophils, eosinophils, and a number of other cell lineages (Schwarz et al., 1995). CD137 is known to have a potent effect on monocytes which are key regulators of the immune response (Pollok et al., 1993). In particular, CD137activated monocytes induce the expression of proinflammatory cytokines and activation markers, and promote adhesion (Schwarz et al., 1993). CD137 also prolongs monocytic survival in vitro (Langstein and Schwarz, 1999). Recently, Kienzle et al. reported that cross-linking of CD137 on monocytes results in increased B lymphocyte apoptosis mediated by direct cell-cell contact (Kienzle and von Kempis, 2000). These data strongly suggest that the function of CD137 is not limited to a costimulatory one on $T$ cells. Instead, CD137 might work as a general ac- 
tivator on inflammatory cells, including monocytes and neutrophils. Therefore, it seems worthwhile to develop in vitro cellular models to further study the possible roles of CD137 in innate immunity and inflammation. In this study we tested the effect of CD137 on the process of monocyte activation in the human monocyte cell line, THP-1.

\section{Materials and Methods}

\section{Preparation and stimulation of cells}

The THP-1 cells were cultured in RPMI 1640 medium (RPMI, Gibco BRL) supplemented with $10 \%$ fetal calf serum (FCS, Hyclone, Logan, UT), $50 \mathrm{U} / \mathrm{ml}$ penicillin/ streptomycin (Sigma, St. Louis, MO), $50 \mu \mathrm{M}$ 2-mercaptoethanol (Sigma), and $2 \mathrm{mM}$ glutamine (GIBCO $B R L)$. The cells were seeded in 6-well culture plates (Costar, NY) at a density of $1.2 \times 10^{5}$ cells $/ \mathrm{ml}$ and treated with immobilized anti-CD137 monoclonal Ab (mAb, $10 \mu \mathrm{g} / \mathrm{ml})$ for 3 days. For antibody immobilization on the culture plates, antibody diluted in 1 ml PBS ( $\mathrm{pH}$ 7.2) was added to the 6-well culture plates, and the plates were incubated overnight at $4^{\circ} \mathrm{C}$. Unbound Abs were removed by washing with cold PBS.

\section{Antibodies and reagents}

The anti-CD137 mAb was purchased from the Immunomodulation Research Center, University of UIsan, and produced as described (Garni-Wagner et al., 1996). The anti-CD137 mAb was conjugated with FITC for flow cytometry as reported previously (Holmes et al., 1996). An isotype control, mouse $\lg _{1} \kappa$ (MOPC-21), was purchased from Sigma. Anti-CD11bphycoerythrin (PE), anti-CD54-FITC, anti-CD106-FITC, and mouse $\operatorname{lgG}_{1}$ K-PE (or -FITC) antibodies were purchased from PharMingen (San Diego, CA). The anti-human $\mathrm{CD} 137 \mathrm{mAb}$ and isotype control $A b$ were tested for the presence of the endotoxin LPS using the Limulus amoebocyte lysate (LAL) test (Sigma), and the endotoxin contents in the working solution were found to be negligible. LY294002, SB203580, U0126, U0124, NPPB and PD98059 were purchased from Calbiochem-Novabiochem (La Jolla, CA). All reagents used were endotoxin-tested and all plastic wares were endotoxin-free.

\section{Flow cytometric analysis}

Cells $\left(5 \times 10^{5}\right.$ cells $\left./ 50 \mu \mathrm{L}\right)$ were incubated for $30 \mathrm{~min}$ with PE- and FITC-conjugated Abs on ice in the dark. The cells were washed 3 times with HBSS (Gibco $\mathrm{BRL}$ ) containing $2.5 \% \mathrm{FCS}$ and $0.1 \%$ sodium azide (HBSS/FCS/AZ). Cells were further incubated for 30 min with FITC- or PE-conjugated streptavidin on ice if necessary. The cells were washed 3 times, resuspended in $0.5 \mathrm{~mL}$ of $\mathrm{HBSS} / \mathrm{FCS} / \mathrm{AZ}$, and analyzed by flow cytometry using a FACSCalibur (Becton Dickinson, San Jose, CA).

\section{Reverse transcription-polymerase chain reaction (RT-PCR)}

Total RNA was extracted from the THP-1 cells using the RNeasy mini kit (Qiagen, Maryland). PCR was performed as described previously. The following primers were used; human CD137-FF (5'-GTGACATATGCAGGCAGTGTAAAG-3'), human CD137-RF (5'GACTTCCATTTCACAGTTCACATC-3'), human $\beta$ actin-FF (5'-GTGGGGCGCCCCAGGCACCA-3'), and human $\beta$-actin-RF (5'-CTCCTTAATGTCACGCACGATTC-3'). PCR products were separated on $1.2 \%$ agarose gels, and the gels were stained with ethidium bromide.

\section{Adhesion assay}

THP-1 cells were activated by biotin-conjugated antiCD137 mAb and avidin. To rule out adhesion between CD137 on THP-1 cells and anti-CD137 on culture plates, THP-1 cells were incubated with biotinconjugated anti-CD137 $\mathrm{mAb}(1 \mu \mathrm{g} / \mathrm{ml})$ for $30 \mathrm{~min}$ on ice, and then cross-linked with $1 \mathrm{mg} / \mathrm{ml}$ avidin (Sigma) at $37^{\circ} \mathrm{C}$. The cells were seeded into 96 -well flatbottom culture plates precoated with an ECM protein at a density of $5 \times 10^{5}$ cells $/ \mathrm{ml}$. After 3 days, unbound cells were removed by washing 4 times with washing solution (FCS-free RPMI). A biotin-conjugated mouse $\lg G_{1} \kappa$ was used as an isotype control. For attachment to extracellular matrix (ECM) proteins, activated cells were treated with immobilized fibronectin, laminin, and collagen at a concentration of $6 \mu \mathrm{g} / \mathrm{ml}$ in endotoxin-free PBS. After $30 \mathrm{~min}$, unbound cells were removed by washing 4 times with washing solution. A redox indicator, Alamar Blue (Serotec), diluted in culture media $(10 \% \mathrm{v} / \mathrm{v})$ was added to the culture, followed by incubation for $4 \mathrm{~h}$. The plates were read on a Victor ${ }^{2}$ multilabel counter (Wallac, Turku, Finland) at $570 \mathrm{~nm}$ (measurement) and $600 \mathrm{~nm}$ (reference). The specific absorbance values were calculated from the following equation: the specific OD $(570-600)=$ sample OD (570-600) - media OD (570-600).

\section{Cytokine ELISA}

The production of cytokines was determined by a cytokine-specific ELISA of the culture supernatants. For IL-8, TNF- $\alpha$, IL-2, IL-4, IL-6, IL-12, IL-18, IFN- $\gamma$, G-CSF, and GM-CSF, a matched Ab pair from PharMingen (Hamburg, Germany) was used according to the manufacturer's instructions.

\section{Western blotting}

THP-1 cells were stimulated as described above and proteins were extracted with lysis buffer $(10 \mathrm{mM}$ Tris- $\mathrm{HCl}$ [pH 7.4], $50 \mathrm{mM} \mathrm{NaCl}, 5 \mathrm{mM}$ EDTA, $30 \mathrm{mM}$ $\mathrm{NaF}, 0.1 \mathrm{mM} \mathrm{Na}_{3} \mathrm{VO}_{4}, 1 \%$ Triton X-100, 0.5\% NP-40, $1 \mathrm{mM}$ PMSF, and protease inhibitor cocktail). Equal amounts of protein from each sample were diluted with $4 \times$ SDS sample buffer, applied to SDS-PAGE gels, separated, and transferred to nitrocellulose mem- 
branes (Millipore, Bedford, MA). Phosphorylated extracellular signal-regulated kinase (ERK)1/2 was detected by Western blotting using an anti-phosphoERK $1 / 2$ antibody as the primary Ab. After the membrane was stripped, ERK1/2 was detected by reprobing with an anti-ERK1/2 $\mathrm{Ab}$. Bound $\mathrm{Abs}$ were detected by enhanced chemiluminescence (ECL; Amersham Pharmacia Biotech, Little Chalfont, UK).

\section{Statistical analyses}

Statistical analyses were done using a Student's $t$ test. Data were considered statistically significant when $P$ was less than 0.05 .

\section{Results}

\section{Expression of CD137 on human monocytic THP-1 cells}

The expression of CD137 protein on THP-1 cells was determined by flow cytometry analysis. THP-1 cells expressed detectable amounts of CD137 protein (Figure $1 \mathrm{~A})$. However, other human monocytic cell lines, HL-60, U937, and K562, did not express CD137 protein (data not shown). To examine whether the expression of CD137 protein correlates with the amount of CD137 mRNA, total RNA was extracted from cells and expression of CD137 mRNA was evaluated using

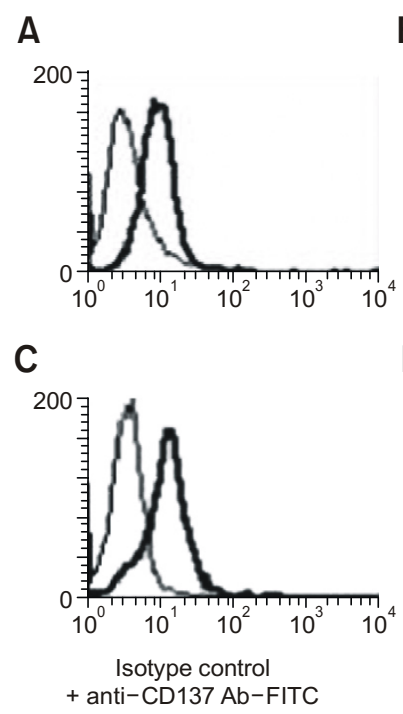

B
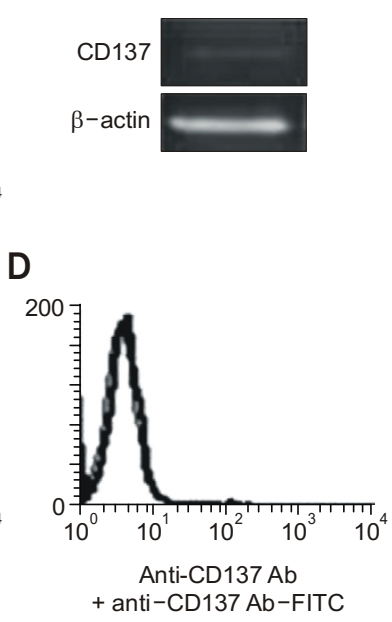

Figure 1. Expression of CD137 in human monocytic THP-1 cells. (A) THP-1 cells were stained with anti-CD137-FITC or isotype controlFITC and analyzed by flow cytometry. THP-1 cells expressed detectable amounts of CD137 surface protein. (B) Total mRNA was extracted from THP-1 cells and analyzed by RT-PCR. Amplification of $\beta$-actin served as an internal control to ensure the use of equal amounts of extracted mRNA. (C) THP-1 cells were pre-stained with isotype control or anti-CD137 mAb for 30 min and incubated with FITC conjugated anti-CD137 mAb. Data are representative of at least two independent experiments.
RT-PCR. In accordance with the results obtained by flow cytometry analysis, CD137 mRNA was detected in THP-1 cells as the expected 594-bp product (Figure $1 \mathrm{~B}$ ). In addition, to confirm the nonspecific binding expression of CD137 protein on THP-1 cells, we looked to see if THP-1 cells pretreated by isotype control or purified anti-CD137 mAb could be stained again with FITC conjugated anti-CD137 mAb. Flow cytometry showed that the expression of CD137 protein was blocked by this mAb (Figure 1C). These results suggest that human monocytic THP-1 cells constitutively express both CD137 protein and mRNA.

\section{Effect of CD137 on the expression of cytokines and chemokines in THP-1 cells}

To address the role of CD137 in monocyte function, THP-1 cells were cultured in plates coated with antiCD137 mAb and analyzed for the production of cytokines and chemokines. The concentrations of cyto-
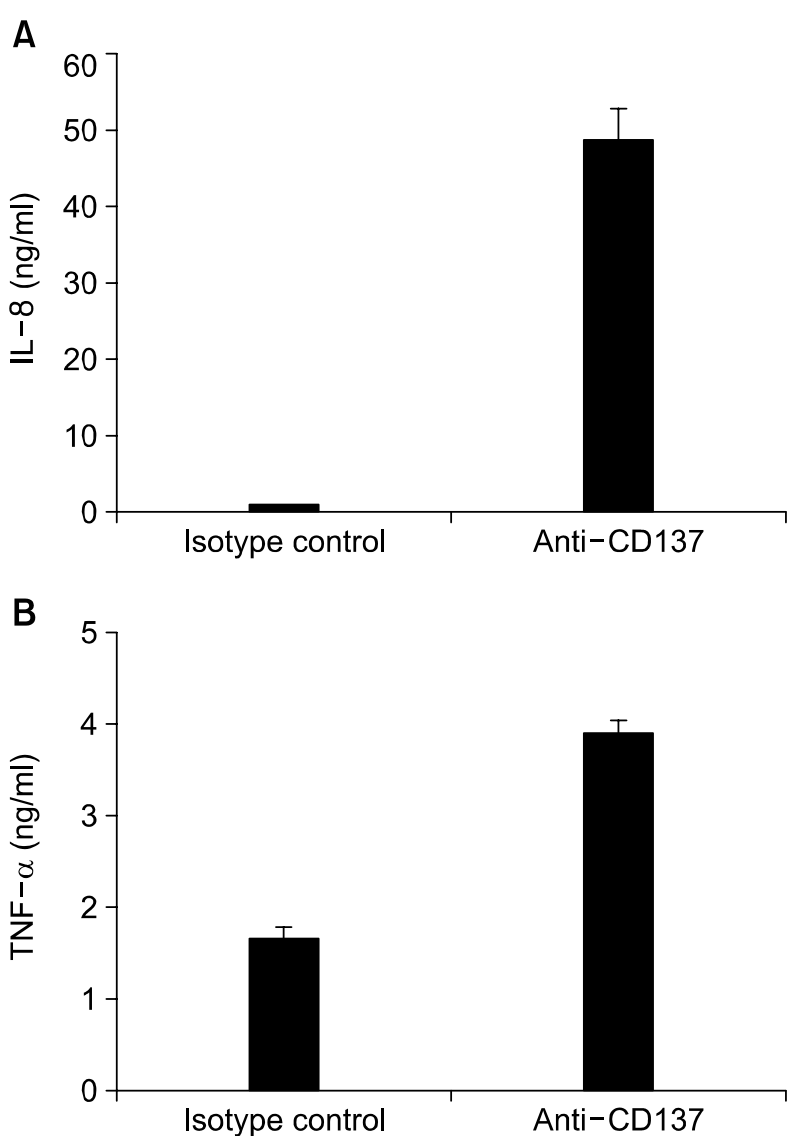

Figure 2. Effect of CD137 on the expression of cytokines and chemokines in THP-1 cells. Culture plates were coated with an isotype control or anti-CD137 mAb at $4^{\circ} \mathrm{C}$ overnight. Unbound Abs were washed off. THP-1 cells were added to the plates and cultured for 3 days. Cytokines in the culture supernatants were measured by ELISA. IL-8 (A) and TNF- $\alpha$ (B) secretion increased significantly when THP-1 cells were treated with anti-CD137 mAb. Data $(n=3)$ are presented as mean \pm SD $(P<0.001)$. 
kines and chemokines in the culture supernatant of THP -1 cells activated with an anti-CD137 mAb for 3 days were measured by ELISA. As shown in Figure 2 , the amounts of IL-8 (Figure 2A) and TNF- $\alpha$ (Figure 2B) were significantly higher in THP-1 cells treated with the anti-CD137 mAb than in cells treated with the isotype control. However, IL-2, IL-4, IL-6, IL-12, IL-18, IFN- $\gamma, \mathrm{G}-\mathrm{CSF}$, and GM-CSF were not detected in the culture supernatants (data not shown).

\section{Effect of CD137 on the expression of adhesion molecules in THP-1 cells}

We monitored THP-1 cell adhesion after cross-linking CD137. Most of the initially round, free-floating THP-1 cells were attached to the plate $12-24 \mathrm{~h}$ after treatment with the anti-CD137 mAb and then became flat in shape (data not shown). To evaluate which adhesion molecules contributed to the cell adhesion of activated THP-1 cells, we used flow cytometry to study the expression of the integrins CD11b, CD54, and CD106 in THP-1 cells. The levels of CD11b and CD54 expression were up-regulated by cross-linking of CD137 with an anti-CD137 mAb, but the expression of CD106 remained unchanged (Figure 3). CD54 protein was up-regulated the most after CD137 cross- linking.

\section{Effect of CD137 on THP-1 cell binding to ECM proteins}

To investigate the involvement of CD137 in THP-1 cell adhesion to ECM proteins, we used an adhesion assay to examine the binding of THP-1 cells to fibronectin, laminin, and collagen. THP-1 cells activated by biotin-conjugated anti-CD137 mAb and avidin were cultured at $37^{\circ} \mathrm{C}$ in culture plates coated with the ECM proteins. Cells that adhered to the ECM-coated plates were separated from those that had not adhered, and adherent cell numbers were compared among the different experimental groups. Compared to the isotype control $A b$ treated cells, a greater proportion of anti-CD137 mAb treated THP-1 cells adhered to the three ECM proteins (Figure 4).

\section{Effect of cell signaling inhibitors on CD137-induced adhesion of THP-1 cells}

We next examined the role of specific signaling pathways in the increased expression of IL-8, TNF- $\alpha$, and adhesion molecules in THP-1 cells treated with the
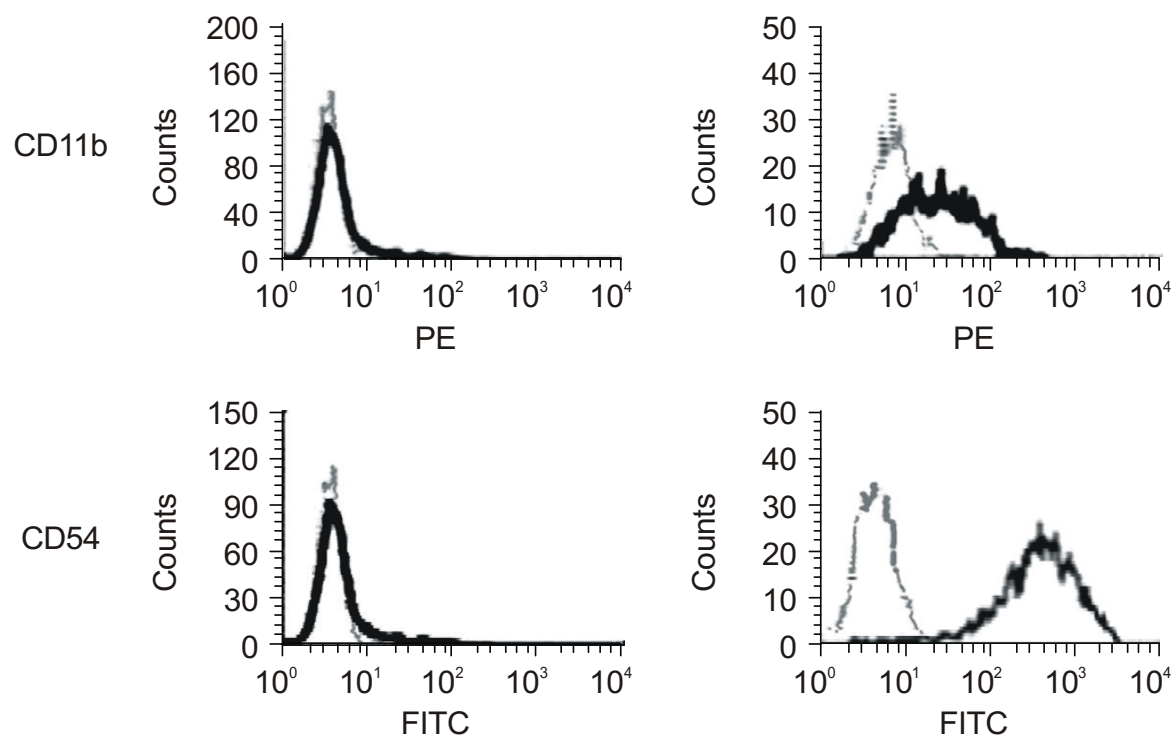

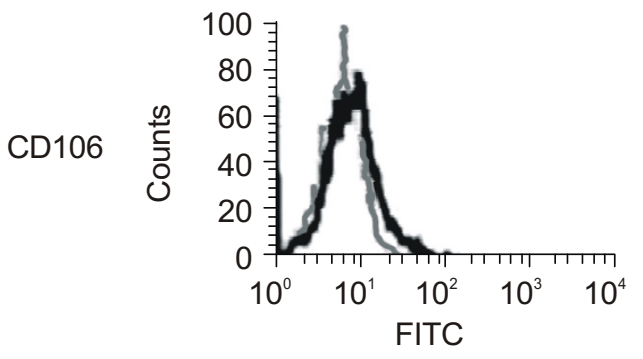

Isotype control

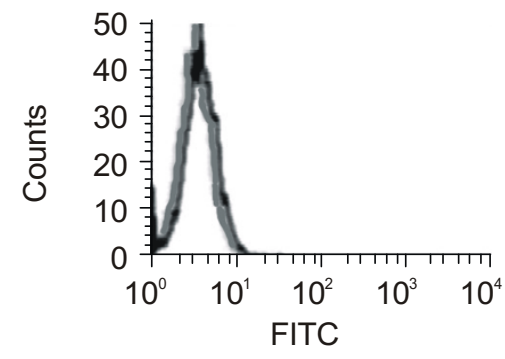

Anti-CD137 Ab
Figure 3. Effect of CD137 on the expression of adhesion molecules in THP. 1 cells. THP-1 cells were cultured with an immobilized isotype control or antiCD137 mAb for 3 days, and stained with antibodies against CD11b, CD54, or CD108, whose expression was then analyzed by flow cytometry. Representative data are shown from three experiments. 


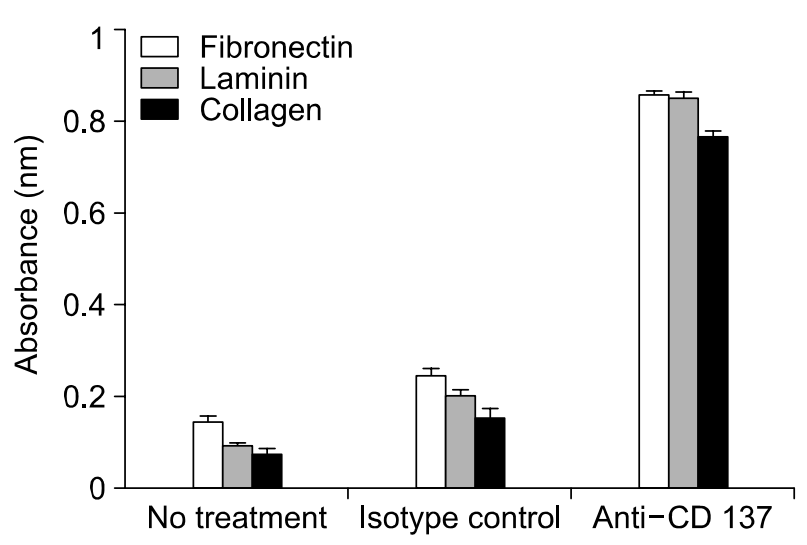

Figure 4. Effect of CD137 on THP-1 cell binding to ECM proteins THP-1 cells activated by immobilized anti-CD137 mAb for 3 days were cultured in a 96-well flat-bottom plate precoated with the ECM proteins, fibronectin, laminin, and collagen at a concentration of 6 $\mu \mathrm{g} / \mathrm{ml}$ for $30 \mathrm{~min}$. After the removal of nonadherent cells by washing 4 times with washing solution, Alamar Blue was added to the cultures and the plates were incubated for $4 \mathrm{~h}$. The absorbance of the culture media was measured using a Victor ${ }^{2}$ multilabel counter. Data $(n=5)$ are presented as mean \pm SEM.

anti-CD137 mAb, using pharmacologic inhibitors specific for kinases in different signaling pathways. As shown in Figure $5 \mathrm{~A}$, pretreatment of THP-1 cells with PD98059 (30 $\mu \mathrm{M})$ and U0126 (5 mM), specific inhibitors of mitogen-activated protein kinase kinase (MEK), attenuated CD137-induced THP-1 binding to culture plates, whereas U0124, an inactive derivative of U0126, had no effect. SB203580 (20 $\mu \mathrm{M})$, a selective p38 MAP kinase inhibitor, LY294002 (20 $\mu \mathrm{M})$, a phosphatidylinositol-3 (PI3)-kinase inhibitor, and NPPB (10 $\mu \mathrm{M})$, a cyclooxygenase inhibitor, also did not significantly affect CD137-induced binding of THP-1 cells to the culture plates. To investigate the specific signaling pathways activated by anti-CD137 mAb treatment of THP-1 cells, we studied the effect of cell signaling inhibitors on the expression of CD11b and CD54 by flow cytometry. CD137-mediated up-regulation of CD11b and CD54 expression was inhibited at the protein level by pretreatment with PD98059 or U0126 (data not shown).

\section{CD137-induced activation of ERK1/2 in THP-1 cells}

We next determined whether cross-linking of CD137 would activate ERK1/2, a downstream component of the MEK signaling pathway. As shown in Figure $5 B$, treatment of THP-1 cells with anti-CD137 mAb (10 $\mu \mathrm{g} / \mathrm{mL}$ ) increased ERK1 and ERK2 phosphorylation. Peak phosphorylation of ERK1/2 was observed at 60 min and declined thereafter. Taken together, these results indicate that cross-linking of CD137 increases the phosphorylation of ERK1/2, apparently via MEK activation.

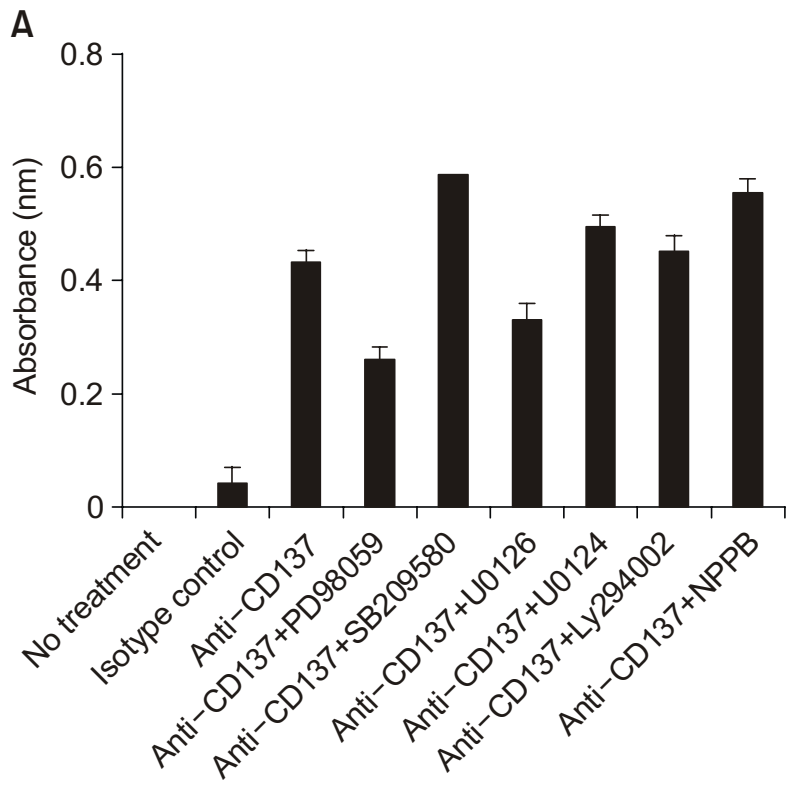

B

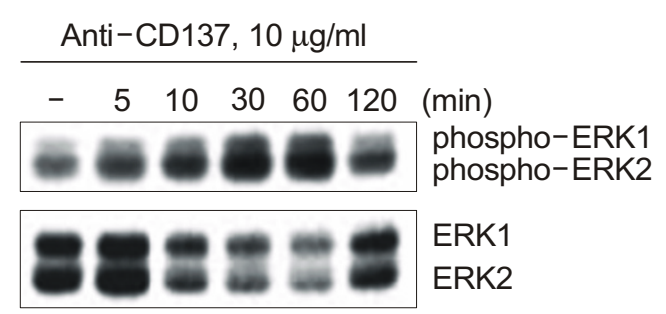

Figure 5. Activation of THP-1 cells with anti-CD137 mAb induces the MEK-ERK1/2 pathway. (A) 96-well plates were coated with isotype control or anti-CD137 mAb at $4^{\circ} \mathrm{C}$ overnight. Unbound antibodies were washed off. THP-1 cells were cultured in the presence of the indicated inhibitors and isotype control or immobilized anti-CD137 mAb for 3 days. After unbound cells were removed by washing 4 times with washing solution, Alamar Blue was added to the cultures, which were then incubated for $4 \mathrm{~h}$. The plates were read on a Victor ${ }^{2}$ multilabel counter. Data $(n=3)$ are presented as mean \pm SEM. (B) THP-1 cells were incubated and then treated with an immobilized anti-CD137 mAb $(10 \mu \mathrm{g} / \mathrm{ml})$ for the indicated time periods. Equal amounts of protein were separated by SDS-PAGE and transferred onto nitrocellulose membranes. Phosphorylated ERK $1 / 2$ was detected by Western blotting using anti-phospho ERK1/2 Abs (upper panel). Blots were stripped and reprobed with Abs specific for unphosphorylated ERK1/2 (lower panel). Representative data are shown from two experiments.

\section{Discussion}

We found in this study that THP-1 cells express CD137 constitutively. More importantly, the binding of THP-1 cell-associated CD137 by an agonistic mAb delivers a stimulatory signal to THP-1 cells, leading to the secretion of inflammatory cytokines, expression of adhesion molecules, and attachment of the cells to ECM through the ERK1/2 pathway.

Since CD137 is expressed at sites of inflammation (Schwarz et al., 1993), and can be expressed by endothelial cells (Broll et al., 2001), CD137 could act 
to enhance inflammatory reactions. Many reports have suggested that CD137 plays an important role in the costimulation of $\mathrm{T}$ cells, which is related to acquired immunity (Crowe et al., 1993; Kim et al., 1993; Hurtado et al., 1995; Shuford et al., 1997). However, some researchers have been interested in monocytes as key regulators of the immune response. Recently several reports have indicated that CD137 expression correlates with dysregulated monocyte activation, such as found in several autoimmune diseases and immune deficiencies (Foell et al., 2004; Jung et al., 2004).

To functionally characterize CD137 in monocytes, we used a well-characterized human monocytic leukemic cell line, THP-1. THP-1 cells provide a relatively uniform population of monocytic cells that can be differentiated into mature macrophage-like cells; THP-1 cells have therefore been used extensively to study gene expression during monocytic differentiation (Tsuchiya et al., 1980; Auwerx, 1991). Although CD137 is expressed on lymphocytes, macrophages, carcinoma cells, and other cell lines of lymphoid and myeloid origin (Schwarz et al., 1993; Salih et al., 2000; Imai et al., 2004), we found that CD137 was constitutively expressed on THP-1 cells isolated from a patient with acute myelocytic leukemia (AML)-M5. Our findings are consistent with the known immunomodulatory properties of CD137, which induce the activation of human peripheral blood monocytes (Kienzle and von Kempis, 2000). We demonstrated that CD137 mRNA and protein were constitutively expressed on THP-1 cells using RT-PCR and flow cytometry.

After cross-linking of CD137 on THP-1 cells, we functionally demonstrated that CD137 increases the concentrations of cytokines and chemokines as measured by ELISA. These results are consistent with the studies of Kienzle et al., who observed increased protein expression of both IL- 8 and TNF- $\alpha$ in primary monocytes after cross-linking CD137 (Kienzle and von Kempis, 2000). IL-8 and TNF- $\alpha$, whose main sources are monocytes and macrophages, act as mediators of inflammation and are cytotoxic for many transformed cells (Strieter et al., 1989; Bonta and BenEfraim, 1993). Thus, IL- 8 and TNF- $\alpha$, whose expression was up-regulated by the binding of anti-CD137 $\mathrm{mAb}$ to CD137 cell-associated THP-1, may have profound effects on the recruitment of macrophages to sites of inflammation and on the development of a proper immune response.

$T$ cells and monocytes utilize adhesion molecules for attachment to ECM proteins and migration through endothelial cells to inflammation sites (Langstein et al., 1998; Kim et al., 1999). In this study, we studied THP-1 cells which have a variety of adhesion molecules on their surfaces that mediate interactions with ECM molecules and other cells. We found that an increase in CD11b and CD54 but not CD108 as measured by flow cytometry. CD54 is an adhesion molecule that promotes cell-cell adhesion and leukocyte migration and that binds to CD11a/CD18 and CD11b/CD18 receptors on leukocytes (van de Stolpe and van der Saag, 1996). CD108 primarily mediates monocyte and lymphocyte adhesion, which are specifically found in atherosclerotic lesions (Ludwig et al., 2004). Cybulsky reported that CD108, but not CD54, plays a critical role in the initiation of atherosclerosis (Cybulsky and Gimbrone, 1992). Hence, we suggest that CD137 may modulate adhesion molecule expression in THP-1 cells through other specific signaling pathways. We also demonstrated that CD137 increases cell adhesion to ECM protein-coated plates. Taken together, these data strongly suggest that THP-1 cells are a good model system for studying the functional role of CD137 in monocytes in vitro.

We evaluated the signaling pathways involved in CD137-mediated induction of adhesion molecules by various pharmacologic inhibitors known to specifically block the activity of certain signaling molecules. Our results showed that a specific inhibitor of MEK, PD98059, reduced the binding of THP-1 cells to the culture plate. A PI3-kinase inhibitor; LY294002, a p38 MAPK inhibitor; SB203580, and a cyclooxygenase inhibitor; NPPB, had no effect on CD137-induced binding of THP-1 cells to the plates. In contrast, Cannons et al reported that CD137-induced p38 MAPK activation is inhibited by the p38-specific inhibitor SB203580 in both a T cell hybridoma and in murine $\mathrm{T}$ cells (Cannons et al., 2000). These data suggest that cross-linking of CD137 in THP-1 cells induces various inflammatory responses through a specific signaling pathway. We next determined if cross-linking of CD137 would activate ERK1/2, a kinase that acts downstream of MEK. As shown in Figure 5B, CD137 ligation increased the phosphorylation of ERK1/2, indicating that CD137-induced signaling in THP-1 cells involves activation of MEK kinase, which would lead to the phosphorylation of ERK1/2. In addition, we demonstrated that CD137-mediated up-regulation of CD54 expression was inhibited at the protein level by pretreatment with PD98059 but not SB203580 (data not shown). In both peripheral blood monocytes and THP-1 cells, the expression of TNF- $\alpha$ induced by placenta growth factor (PIGF) is not inhibited by a selective p38 kinase inhibitor (Chalupny et al., 1992). PIGF causes a time-dependent increase in the phosphorylation of ERK1/2 in THP-1 cells (Selvaraj et al., 2003). In the present study, CD137-mediated activation of THP-1 cells showed effects similar to those of PIGF, including expression of proinflammatory cytokines in monocytes.

In summary, we have demonstrated that THP-1 cells express CD137 constitutively. CD137 causes activation of THP-1 cells, resulting in the generation of proinflammatory cytokines, expression of adhesion molecules, and attachment to ECM proteins through the ERK1/2 pathway. Therefore, we suggest that CD137 may significantly contribute to the induction and maintenance of inflammatory responses in monocytes. Additionally, CD137-mediated changes might be useful for controlling monocyte- or macrophagerelated human disease. 


\section{Acknowledgment}

This work was supported by the Interdisciplinary Research Grant (R01-2002-000-00267-0) from the Korea Science and Engineering Foundation and the Korea Ministry of Science and Technology.

We thank Dr. B. Kwon (Immunomodulation Research Center, Ulsan University, Korea) for providing the anti-CD137 antibodies.

\section{References}

Auwerx J. The human leukemia cell line, THP-1: a multifacetted model for the study of monocyte-macrophage differentiation. Experientia 1991;47:22-31

Bonta IL, Ben-Efraim S. Involvement of inflammatory mediators in macrophage antitumor activity. J Leukoc Biol 1993; 54:613-26

Broll K, Richter G, Pauly S, Hofstaedter F, Schwarz H. CD137 expression in tumor vessel walls. High correlation with malignant tumors. Am J Clin Pathol 2001;115:543-9

Cannons JL, Choi Y, Watts YH. Role of TNF receptorassociated factor 2 and p38 mitogen-activated protein kinase activation during 4-1BB-dependent immune response. J Immunol 2000;165:6193-204

Chalupny NJ, Peach R, Hollenbaugh D, Ledbetter JA, Farr AG, Aruffo A. T-cell activation molecule CD137 binds to extracellular matrix proteins. Proc Natl Acad Sci USA 1992;89: 10360-4

Crowe PD, VanArsdale TL, Goodwin RG, Ware CF. Specific induction of $80-\mathrm{kDa}$ tumor necrosis factor receptor shedding in $T$ lymphocytes involves the cytoplasmic domain and phosphorylation. J Immunol 1993;151:6882-90

Cybulsky MI, Gimbrone M. Endothelial-leukocyte adhesion molecules in acute inflammation and atherosclerosis. In Endothelial Cell Dysfunction (Simionescu N, Simionescu M, des) 1992, Plenum Press, New York, NY

Foell JL, Diez-Mendiondo BI, Diez OH, Holzer U, Ruck P, Bapat AS, Hoffmann MK, Mittler RS, Dannecker GE. Engagement of the CD137 (4-1BB) costimulatory molecule inhibits and reverses the autoimmune process in collageninduced arthritis and establishes lasting disease resistance. Immunology 2004;113:89-98

Garni-Wagner BA, Lee ZH, Kim YJ, Wilde C, Kang CY, Kwon BS. CD137 is expressed on CD45RAhiROhi transitional T cell in humans. Cell Immunol 1996;169:91-8

Gottlieb AB, Lahita RG, Chiorazzi N, Kunkel HG. Immune function in systemic lupus erythematosus. Impairment of in vitro T-cell proliferation and in vivo antibody response to exogenous antigen. J Clin Invest 1979;63:885-92

Holmes K, Fowlkes BJ, Schmid I, Giorgi JV. Preparation of cells and reagents for flow cytometry. In Current protocols in immunology (Coligan JE, Kruisbeek AM, Margulies DH, Shevach EM, Strober W, eds), 1996, John Wiley \& Sons, New York, NY

Hurtado JC, Kim SH, Pollok KE, Lee ZH, Kwon BS. Potential role of $4-1 \mathrm{BB}$ in $\mathrm{T}$ cell activation. Comparison with the costimulatory molecule CD28. J Immunol 1995;155:3360-7

Imai C, Mihara K, Andreansky M, Nicholson IC, Pui $\mathrm{CH}$, Geiger TL, Campana D. Chimeric receptors with 4-1BB signaling capacity provoke potent cytotoxicity against acute lymphoblastic leukemia. Leukemia 2004;18:676-84

Janeway CA Jr, Travers P, Walport M, Shlomchik MJ. Immunobiology, 5th Ed, 2001, Garland, New York, NY

Jung HW, Choi SW, Choi JI, Kwon BS. Serum concentrations of soluble 4-1BB and 4-1BB ligand correlated with the disease severity in rheumatoid arthritis. Exp Mol Med 2004;36:13-22

Kienzle G, von Kempis J. CD137 (ILA/CD137), expressed by primary human monocytes, induces monocyte activation and apoptosis of B lymphocytes. Int Immunol 2000;12:73-82

Kim J, Choi SP, La S, Seo JS, Kim KK, Nam SH, Kwon B. Constitutive expression of $4-1 B B$ on $T$ cells enhances CD4+ $T$ cell responses. Exp Mol Med 2003;35:507-17

Kim YJ, Mantel PL, June CH, Kim SH, Kwon BS. 4-1BB costimulation promotes human $\mathrm{T}$ cell adhesion to fibronectin. Cell Immunol 1999;192:13-23

Langstein J, Michel J, Fritsche J, Kreutz M, Andreesen R, Schwarz H. CD137 (ILA/4-1BB), a member of the TNF receptor family, induces monocyte activation via bidirectional signaling. J Immunol 1998;160:2488-94

Langstein J, Schwarz H. Identification of CD137 as a potent monocyte survival factor. J Leuk Biol 1999;65:829-33

Ludwig A, Lorenz M, Grimbo N, Steinle F, Meiners S, Bartsch C, Stangl K, Baumann G, Stangl V. The tea flavonoid epigallocatechin-3-gallate reduces cytokine-induced VCAM-1 expression and monocyte adhesion to endothelial cells. Biochem Biophys Res Commun 2004;316:659-65

Pollok KE, Kim YJ, Zhou Z, Hurtado JC, Kim KK, Pickard $\mathrm{KK}$, Kwon BS. Inducible T cell antigen CD137 analysis of expression and function. J Immunol 1993;150:771-81

Salih HR, Kosowski SG, Haluska VF, Starling GC, Loo DT, Lee $F$, Aruffo AA, Trail PA, Kiener PA. Constitutive expression of functional 4-1BB (CD137) ligand on carcinoma cells. J Immunol 2000;165:2903-10

Schwarz H, Tuckwell J, Lotz M. A receptor induced by lymphocyte activation (ILA): a new member of the human nerve growth factor/tumor necrosis factor receptor family. Gene 1993;134:295-8

Schwarz H, Valbracht J, Tuckwell J, von Kempis J, Lotz M. ILA, the human CD137 homologue, is inducible in lymphoid and other cell lineages. Blood 1995;85:1043-52

Selvaraj SK, Giri RK, Perelman N, Johnson C, Malik P, Kalra VK. Mechanism of monocyte activation and expression of proinflammatory cytochemokines by placenta growth factor. Blood 2003;102:1515-24

Shuford WW, Klussman K, Tritchler DD, Loo DT, Chalupny $J$, Siadak AW, Brown TJ, Emswiler J, Raecho H, Larsen CP, Pearson TC, Ledbetter JA, Aruffo A, Mittler RS. 4-1BB costimulatory signals preferentially induce $\mathrm{CD} 8+\mathrm{T}$ cell proliferation and lead to the amplification in vivo of cytotoxic T cell responses. J Exp Med 1997;186:47-55 
Strieter RM, Remick DG, Lynch JP, Genord M, Raiford C, Spengler R, Kunkel SL. Differential regulation of tumor necrosis factor-alpha in human alveolar macrophages and peripheral blood monocytes: a cellular and molecular analysis. Am J Respir Cell Mol Biol 1989;1:57-63

Traycoff RB, Pascual E, Jr Schumacher HR. Mononuclear cells in human synovial fluid. Identification of lymphoblasts in rheumatoid arthritis. Arthritis Rheum 1976;19:743-8
Tsuchiya S, Yamabe M, Yamaguchi Y, Kobayashi Y, Konno $Y$, Tada K. Establishment and characterization of a human acute monocytic leukemia cell line (THP-1). Int $\mathrm{J}$ Cancer 1980;2:171-6

van de Stolpe A, van der Saag PT. Intercellular adhesion molecule-1. J Mol Med 1996;74:13-33 